\title{
RELATIONSHIP OF SELF-COMPASSION AND DIVORCE READINESS IN WOMEN SUBMITTING DIVORCE LAWSUIT IN SURABAYA RELIGIOUS COURTS
}

\author{
Handajani A*, Gunadi IGN** \\ * Dokter Umum, Peserta PPDS I Prodi Psikiatri Departemen/SMF Ilmu Kedokteran Jiwa FK UNAIR/RSUD Dr. Soetomo Surabaya \\ Puslitbang Humaniora dan Manajemen Kesehatan Kementerian Kesehatan RI \\ ** Psikiater Konsultan, Staf Pengajar Departemen / SMF Ilmu Kedokteran Jiwa FK Universitas Airlangga / RSUD Dr. Soetomo Surabaya
}

\begin{abstract}
Background. The higher increase in divorce each year are often triggered by prolonged marital conflict without a complete settlement, of which $70 \%$ occurred due to divorce by wives with primary reason is disharmony. The divorce decision often made without proper preparation, lead to a bad impact on later life. Self-compassion involved in producing a firmness choices supported by self-confidence and lack of ambivalence in the decision to divorce.

Objective. To analyze the relationship between self-compassion with the female complainant divorced readiness in the Religious Court Surabaya.

Methods. The study analytic correlation with cross sectional design using systematic random sampling and research instruments using the Self-Compassion Scale (SCS) to assess self-kindness, self-judgment, common humanity, isolation, mindfulness, overidentification, as well as Divorce Readiness Questionnaire (Gregg) and a culture questionnaire to assess the readiness of divorce. Results. There were 46 study subjects met the inclusion criteria. Pearson Correlation Test declare that self-compassion had no correlation with the readiness of divorce ( $p=0.083$, Gregg, and $p=0.259$, culture).

Conclusion. There is no relationship between self-compassion with a divorced readiness. Timing of research (timing) and external factors (Javanese culture) more strongly affect the subject of research for the time being, thus making the correlation was not significant.
\end{abstract}

Keywords: self-compassion, divorce readiness, self-compassion domain

Corresponding author: Adianti Handajani, dr.

Dep/SMF Kedokteran Jiwa FK UNAIR/RSUD Dr.Soetomo Surabaya

Puslitbang Humaniora dan Manajemen Kesehatan Kementerian Kesehatan RI HP: 081330915808 | email: handajaniadianti@yahoo.co.id 


\section{PENDAHULUAN}

Indonesia merupakan salah satu negara dengan tingkat perceraian cukup tinggi. Hal ini dibuktikan, dimana tingkat perceraian di Indonesia menempati urutan tertinggi se Asia Pasifik pada tahun 2013, diikuti angka perceraian yang semakin meningkat di tahun-tahun berikutnya. Data Kementerian Agama RI menunjukkan peningkatan 10 persen angka perceraian (216.286) tahun 2009, peningkatan 3 persen (285.184) tahun 2010, dan peningkatan menjadi 14,6 persen (324.527) tahun 2013. Badan Peradilan Agama Mahkamah Agung menyampaikan bahwa kota Surabaya menempati tingkat perceraian tertinggi dalam periode tahun 2010 hingga 2014, yang sebelumnya diduduki oleh kota Bandung.

Perceraian bukanlah impian sebuah perkawinan, namun perkawinan abadi dan menjadi orang tua adalah harapan setiap pasangan menikah. Ketika kebiasaan, harapan, komitmen, dan komunikasi tidak sesuai dengan kenyataan, maka ketegangangan-ketegangan menghadapi masalah kecil sering muncul di antara pasangan. Ketidaksesuaian ini dapat berlarut-larut hingga menghasilkan konflik rumah tangga yang tidak pernah tuntas penyelesaiannya, sehingga solusi perceraian seringkali dilakukan tanpa persiapan matang karena berlandaskan emosi dan perasaan ambivalen [1,2].

Sebenarnya perkawinan dapat dipertahankan bila pasangan dapat melakukan kesepakatan untuk tetap bersama yang berkelanjutan dan sukses [3]. Kesuksesan dalam sebuah kesepakatan perlu dilandasi self-compassion yang tinggi pada masing-masing pasangan. Demikian pula pada perkawinan yang sedang mengalami badai bahkan kondisi perceraian, self-compassion sangat dibutuhkan. Self-compassion terdiri dari 6 komponen, yaitu selfkindness (sikap baik pada diri), common humanity (pemahaman akan kemanusiaan), mindfulness (kesadaran penuh pada diri), self judgment (otokritik dan penghakiman pada diri), isolation (keterpisahan dari orang lain), overidentification (perenungan berlebih pada kegagalan) [4].

Self-compassion adalah memberikan pemahaman dan kebaikan kepada diri sendiri ketika menghadapi penderitaan, mengalami kegagalan, ataupun membuat kesalahan dengan tidak menghakimi terhadap kekurangan, ketidaksempurnaan, kegagalan seseorang, mengakui bahwa pengalaman sendiri adalah bagian dari pengalaman manusia yang umum, mengamati pikiran dan perasaan sesuai kondisi diri tanpa berusaha menekan/menolak kondisinya, tidak over-identification, dan lebih memahami emosi negatif diri [4-6]. Dengan demikian, berjalannya proses perceraian yang dilandasi suatu pemahaman diri, kematangan emosi maupun perbaikan emotional coping skills dari masing-masing pasangan akan menghasilkan suatu ketegasan pilihan yang didukung rasa percaya diri dan ketiadaan ambivalen dalam penentuan keputusan [2]. Sedangkan self-compassion yang rendah seringkali membuat pasangan tidak siap dalam mempertahankan perkawinan yang telah mereka bina selama bertahun-tahun, padahal ketidaksiapan perceraian cukup besar dalam memberikan dampak yang berarti terhadap kesehatan fisik, psikologis, serta kerentanan terhadap perilaku berisiko baik pada pasangan maupun anak-anak mereka nantinya [7]. Individu dengan self-compassion rendah akan cenderung menarik diri dari orang lain, menganggap kegagalan perkawinan adalah sebuah kesalahan besar yang tidak bisa diperbaiki, selalu memiliki perspektif sempit bahwa hanya dirinyalah yang mengalami kegagalan. Hal ini akan memudahkan seseorang jatuh dalam kondisi depresi, dan bila berkelanjutan tentunya akan mengganggu kualitas hidup seseorang baik dalam berkomunikasi dengan pasangan, bekerja, maupun dalam memberikan pola asuh yang baik kepada anak-anak mereka.

Oleh karena itu, jika masing-masing pasangan perkawinan mempunyai self-compassion tinggi, maka perceraian dalam perkawinan kemungkinan dapat dicegah. Namun hal ini belum bisa dipastikan, karena beberapa faktor dapat mempengaruhi perceraian meskipun salah satu dari pasangan merupakan seseorang yang bijaksana. Faktor-faktor tersebut meliputi komitmen dan harapan yang tidak sesuai realitas, perkawinan merupakan jenis hubungan menantang, kurangnya waktu dan usaha untuk mengembangkan keterampilan hubungan dalam mempertahankan perkawinan [8]. Berkaitan dengan hal tersebut, serta belum terdapatnya penelitian mengenai hubungan antara self compassion dengan kesiapan bercerai sampai saat ini, maka peneliti ingin membuktikan hipotesis dalam penelitian ini, apakah memang terdapat hubungan antara kedua variabel tersebut. Studi Haynes [9] dan 
Ahrons [10] mengemukakan bahwa perceraian sebenarnya masih bisa terselamatkan bila pasangan perkawinan sempat menemui psikiater ataupun konselor perkawinan saat berada dalam proses perceraian emosional, karena mereka dapat diarahkan berpikir lebih jernih dalam menentukan pilihan terbaik sesuai kesepakatan bersama di antara pasangan.

\section{METODE PENELITIAN}

Penelitian ini merupakan penelitian analitik observasional yang bersifat cross sectional untuk menganalisis hubungan antara self compassion dengan kesiapan bercerai. Pengambilan subyek penelitian dilakukan dengan cara tehnik random sampling sistematis (Systematic Random Sampling) dengan cara subyek penelitian dipilah berdasarkan kriteria inklusi dan eksklusi yang telah ditentukan, lalu urutan subyek penelitian diambil setiap kelipatan 5 subyek penelitian. Penentuan sehari sebanyak 5 subyek penelitian. Hasil penyaringan secara keseluruhan berjumlah 46 perempuan pengaju gugatan perceraian di Pengadilan Agama Surabaya, periode April-Agustus 2016. Kriteria inklusi meliputi ; perempuan, usia 16-50 tahun, suku Jawa, baru di tahap awal pengajuan gugatan, alasan perceraian; kekerasan verbal (verbal violence), ekonomifinansial, perilaku buruk (perjudian, minuman keras, narkoba) atau perselingkuhan, bisa membaca dan menulis dalam bahasa Indonesia, bersedia ikut dengan menandatangani informed consent. Kriteria ekslusi; kehamilan di luar ikatan perkawinan, kekerasan dalam rumah tangga (fisik), menderita gangguan jiwa berat, menderita penyakit fisik berat (tidak bisa sembuh), dan sedang menjalani proses pidana. Parameter SelfCompassion diukur dengan Self-Compassion Scale (SCS) [8], pengukuran kesiapan bercerai dengan kuesioner Divorce Readiness Questionnaire [16] dan kesiapan bercerai (sesuai kultur budaya subyek penelitian) dengan kuesioner yang dibuat peneliti mengacu pada Positive Psychological Assessment a Handbook of Models and Measures [17].

\section{HASIL PENELITIAN}

Peneliti berada di ruang tunggu para pengaju gugatan peceraian di Pengadilan Agama saat wawancara dan pengisian kuesioner dilakukan, mengingat ruangan petugas yang tidak memungkinkan. Tidak semua bersedia sebagai subyek peneltian dengan alasan : tergesa-gesa karena keterbatasan waktu, rasa takut karena diancam pasangan, rasa takut karena dilarang keluarga, maupun menolak tanpa alasan. Kesulitan memperoleh subyek penelitian inilah yang memperpanjang waktu pengambilan data di lapangan. Jumlah subyek penelitian sebanyak 46 orang telah masuk kriteria inklusi, 7 orang menolak, 3 orang terhenti (karena berpindah ruangan). Hambatan yang sangat mengganggu adalah suasana yang tidak kondusif (hilir mudik orang dengan suasana penuh ketegangan dan kecemasan).

\section{Tabel 1 Karakteristik Demografi Subyek Penelitian}

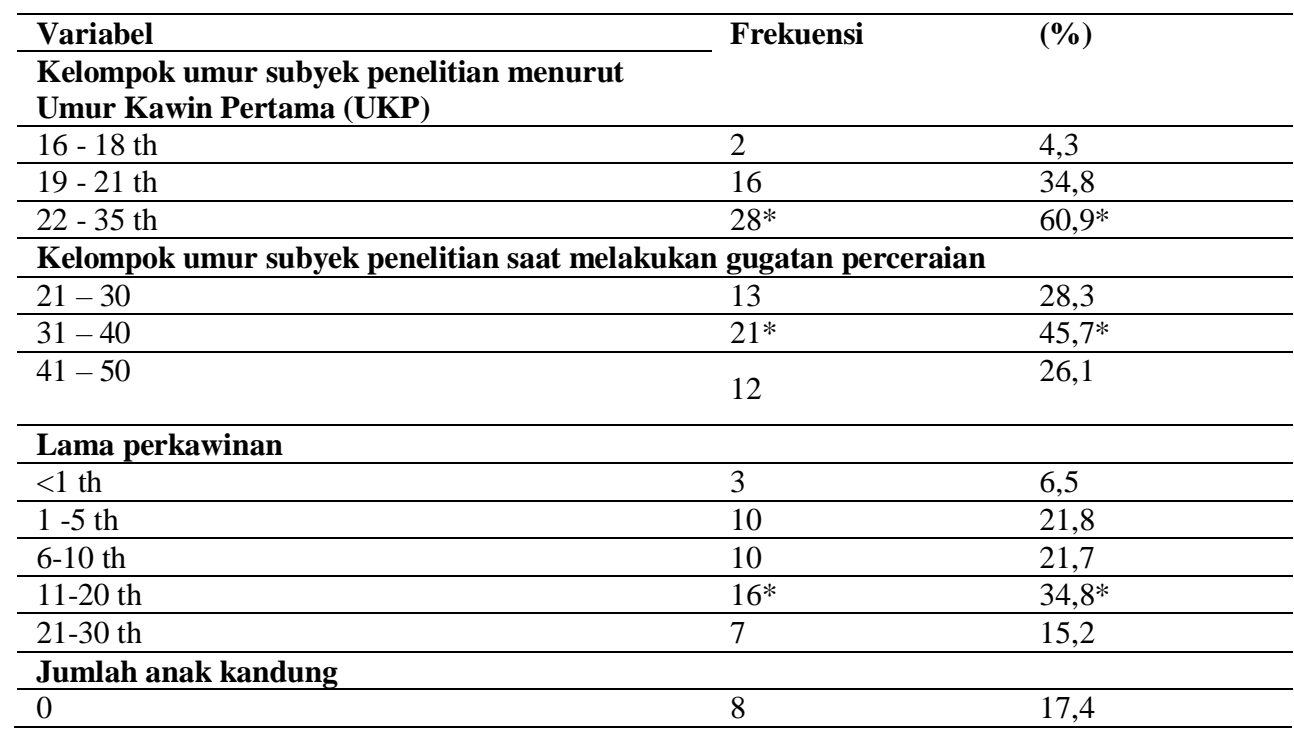




\begin{tabular}{lll}
\hline 1 & $16^{*}$ & $34,8^{*}$ \\
\hline 2 & 12 & 26,1 \\
\hline$\geq 3$ & 10 & 21,7 \\
\hline Pendidikan subyek penelitian & & \\
\hline Tamat SD/sederajat & 4 & 8,7 \\
\hline Tamat SMP/sederajat & 7 & 15,2 \\
\hline Tamat SMA/sederajat & $28^{*}$ & $60,9^{*}$ \\
\hline Akademi-Perguruan Tinggi & 7 & 15,2 \\
\hline Jenis pekerjaan subyek penelitian & & \\
\hline Tidak bekerja & 2 & 4,3 \\
\hline PNS & 1 & 2,2 \\
\hline Swasta & $39^{*}$ & $84,8^{*}$ \\
\hline Wiraswasta & 4 & 8,7 \\
\hline Pendapatan RT per bulan & & \\
\hline$<$ Rp 2.000.000,00 & 9 & 19,6 \\
\hline Rp 2.000.000,00 - Rp 3.000.000,00 & $35^{*}$ & $76,1^{*}$ \\
\hline$>$ Rp 3.000.000,00 & 2 & 4,3 \\
\hline Total & 46 & 100,0 \\
\hline
\end{tabular}

Tabel 1 menunjukkan bahwa perempuan pengaju gugatan perceraian di Pengadilan Agama Surabaya terbanyak menurut umur kawin pertama berada di kelompok 22-35 tahun (60,9\%), kelompok umur terbanyak saat melakukan gugatan perceraian adalah 31-40 tahun $(45,7 \%)$. Lama perkawinan rentang $11-20$ tahun $(34,8 \%)$, sebagian besar baru memiliki seorang anak (34,8\%).
Pendidikan tingkat SMA/sederajat $\quad(60,9 \%$ subyek penelitian; 30-65,2\% suami). Jenis pekerjaan terbanyak swasta (82,6\% subyek penelitian; $69,5 \%$ suami). Pendapatan RT per bulan di kisaran Rp 2.000.000,00 sampai Rp 3.000.000,00 pada 35 RT $(76,1 \%)$. Sebagian besar penghasilan suami lebih tinggi daripada istri $(58,7 \%)$. Namun, 15,2\% menyatakan suami tidak berpenghasilan.

Tabel 2. Karakteristik Perkawinan Subyek Penelitian [18]

\begin{tabular}{|c|c|c|}
\hline Variabel & Frekuensi & $(\%)$ \\
\hline \multicolumn{3}{|l|}{ Dasar perkawinan } \\
\hline Pilihan sendiri & $41^{*}$ & $89,2 *$ \\
\hline Dijodohkan orangtua & 2 & 4,3 \\
\hline Dikenalkan teman/saudara/tokoh agama & 3 & 6,5 \\
\hline \multicolumn{3}{|l|}{ Komitmen di awal perkawinan } \\
\hline Ada & $31^{*}$ & $67,4^{*}$ \\
\hline Tidak ada & 15 & 32,6 \\
\hline \multicolumn{3}{|l|}{ Komitmen di akhir perkawinan } \\
\hline Tidak ada komitmen di awal \& akhir & 14 & 30,4 \\
\hline Dilaksanakan hanya sesaat & 13 & 28,3 \\
\hline Tidak dilaksanakan & $18^{*}$ & $39,1^{*}$ \\
\hline Dilupakan & 1 & 2,2 \\
\hline \multicolumn{3}{|l|}{ Harapan dalam perkawinan } \\
\hline Membina keluarga samawa dilandasi kejujuran & 13 & 28,2 \\
\hline Bisa membimbing istri dan merawat anak & 1 & 2,2 \\
\hline Suami mengijinkan istri bekerja & 1 & 2,2 \\
\hline Perkawinan berjalan sesuai rencana & 1 & 2,2 \\
\hline Perkawinan 1 kali selamanya dan langgeng & $19 *$ & $41,2 *$ \\
\hline Tidak ada, karena perkawinan dipaksakan & 1 & 2,2 \\
\hline Subyek penelitian tidak mengisi & 9 & 19,6 \\
\hline Bisa membeli rumah dalam perkawinan & 1 & 2,2 \\
\hline \multicolumn{3}{|c|}{ Waktu munculnya tanda awal keretakan hubungan } \\
\hline$<1$ th & 11 & 24 \\
\hline $1-2$ th & $12^{*}$ & $26,1^{*}$ \\
\hline $3-5$ th & 10 & 21,7 \\
\hline $6-10$ th & 6 & 13,0 \\
\hline $11-15$ th & 4 & 8,7 \\
\hline $16-20$ th & 3 & 6,5 \\
\hline \multicolumn{3}{|l|}{ Lamanya konflik } \\
\hline 6 bln & 7 & 15,4 \\
\hline $1-2$ th & 10 & 21,7 \\
\hline
\end{tabular}




\begin{tabular}{|c|c|c|}
\hline $3-6$ th & 12 & 26,0 \\
\hline $7-10$ th & 4 & 8,6 \\
\hline$>10$ th & $13^{*}$ & $28,3^{*}$ \\
\hline \multicolumn{3}{|l|}{ Sumber konflik } \\
\hline Ketidakcocokkan kebutuhan \& harapan & $19^{*}$ & $41,3^{*}$ \\
\hline Kesulitan menerima perbedaan & 10 & 21,7 \\
\hline Masalah keuangan & 5 & 10,9 \\
\hline Cemburu \& rasa memiliki berlebihan & 1 & 2,2 \\
\hline Kegagalan komunikasi & 2 & 4,3 \\
\hline Kekerasan verbal & 1 & 2,2 \\
\hline Masalah seksual & 1 & 2,2 \\
\hline Perselingkuhan & 6 & 13,0 \\
\hline Perilaku buruk (NAPZA, judi, minuman keras) & 1 & 2,2 \\
\hline \multicolumn{3}{|l|}{ Sikap menghadapi konflik } \\
\hline Menekan pikiran/perasaan sedih & $20^{*}$ & $43,5^{*}$ \\
\hline Menutupi kelemahan, mencari kepuasan lain & 15 & 32,6 \\
\hline Marah, berteriak & 2 & 4,3 \\
\hline Meluapkan kemarahan pada orang lain & 1 & 2,2 \\
\hline Mengurangi sedih dengan mengatakan yg baik & 3 & 6,5 \\
\hline Berdandan/bergaya seperti orang lain & 1 & 2,2 \\
\hline Memukul diri sendiri bila marah & 1 & 2,2 \\
\hline Tdk menuruti keinginan jelek,sikap berlawanan & 1 & 2,2 \\
\hline Tingkah laku seperti anak-anak & 2 & 4,3 \\
\hline \multicolumn{3}{|l|}{ Cara atasi konflik } \\
\hline Menghadap & $34 *$ & $74,0^{*}$ \\
\hline Berkompromi & 6 & 13,0 \\
\hline Menghindar & 6 & 13,0 \\
\hline \multicolumn{3}{|c|}{ Riwayat pernah berpikir menjaga tidak bercerai dalam perkawinan } \\
\hline Pernah & $37 *$ & $80,4^{*}$ \\
\hline Tidak pernah & 9 & 19,6 \\
\hline \multicolumn{3}{|l|}{ Riwayat pernah berpikir cerai di awal perkawinan } \\
\hline Pernah & 5 & 10,9 \\
\hline Tidak pernah & 37 & $80,4^{*}$ \\
\hline Baru terpikir sekarang & 4 & 8,7 \\
\hline \multicolumn{3}{|l|}{ Waktu mulainya mpy pikiran untuk cerai } \\
\hline Awal-6 bln perkawinan & 4 & 8,7 \\
\hline Setelah 7 bln-2 th perkawinan & 9 & 19,6 \\
\hline Setelah 3-6 th perkawinan & 7 & 15,2 \\
\hline Setelah 7-10 th perkawinan & 6 & 13,0 \\
\hline Setelah $>10$ th perkawinan & $20^{*}$ & $43,5^{*}$ \\
\hline \multicolumn{3}{|l|}{ Dukungan suami terhadap gugatan cerai } \\
\hline Tidak mengetahui & 6 & 13,0 \\
\hline Sebatas mengetahui & 6 & 13,0 \\
\hline Mengetahui \& tidak mendukung & 7 & 15,2 \\
\hline Mengetahui \& mendukung & $14^{*}$ & $30,4^{*}$ \\
\hline Tidak peduli & 13 & 28,4 \\
\hline \multicolumn{3}{|l|}{ Dukungan keluarga besar terhadap gugatan cerai } \\
\hline Tidak mengetahui & 2 & 4,3 \\
\hline Sebatas mengetahui & 6 & 13,0 \\
\hline Mengetahui \& tidak mendukung & 6 & 13,0 \\
\hline Mengetahui \& mendukung & $29^{*}$ & $63,2^{*}$ \\
\hline Tidak peduli & 3 & 6,5 \\
\hline \multicolumn{3}{|c|}{ Hal yang dilakukan bersama suami sebelum gugatan cerai diajukan } \\
\hline Ttidak pernah membicarakan sebelumnya & 18 & 39,1 \\
\hline $\begin{array}{l}\text { Ada pembicaraan, tapi tidak pernah mencapai } \\
\text { kesepakatan bersama }\end{array}$ & $19^{*}$ & $41,3^{*}$ \\
\hline $\begin{array}{l}\text { Ada pembicaraan, mencapai kesepatan bersama, } \\
\text { tetapi tidak membahas rencana ke depan }\end{array}$ & 8 & 17,4 \\
\hline $\begin{array}{l}\text { Ada pembicaraan, mencapai kesepakatan bersama, } \\
\text { telah dipikirkan rencana ke depan }\end{array}$ & 1 & 2,2 \\
\hline \multicolumn{3}{|l|}{ Permasalahan bila gugatan cerai disetujui } \\
\hline Masalah anak & 8 & 17,5 \\
\hline Masalah dengan suami \& keluarga besar & 5 & 10,8 \\
\hline Tidak ada masalah & $33^{*}$ & $71,7^{*}$ \\
\hline Total & 46 & 100,0 \\
\hline
\end{tabular}


Tabel 2 menunjukkan karaktristik subyek penelitian terbanyak, dimana $84,8 \%$ tidak ada perceraian dan keretakan RT orangtua, $89,2 \%$ perkawinan berdasarkan pilihan sendiri, $67,4 \%$ menyatakan ada komitmen di awal perkawinan, tetapi hanya dilaksanakan sesaat $(28,3 \%)$. Harapan perkawinan hanya satu kali dan selamanya $(21,6 \%)$, hanya satu subyek penelitian yang menyatakan tidak memiliki harapan karena perkawinan yang dipaksakan. Keretakan hubungan dirasakan setelah $1-2$ th perkawinan $(26,1 \%)$. Bila perkawinan bertahan, maka lama berlangsungnya konflik biasanya lebih dari 10 tahun $(28,3 \%)$. Sumber konflik akibat ketidakcocokkan antara kebutuhan dan harapan pada $(41,3 \%)$. Subyek penelitian cenderung menekan pikiran/perasaan sedih (43,5\%), namun mereka lebih banyak langsung menghadapi suami dalam mengatasi konflik (74,0\%). Mereka pernah berpikir menjaga agar tidak bercerai dalam perkawinannya dan tidak pernah berpikir untuk cerai di awal perkawinannya (80,4\%), tetapi mulai berpikir ke arah perceraian didapatkan setelah menjalani lebih dari 10 tahun perkawinan (43,5\%). Dukungan terhadap gugatan cerai $(30,4 \%)$ nya diketahui dan didukung suami dan $(63,2 \%)$ diketahui dan didukung oleh keluarga besar. Sebelum gugatan cerai diajukan, (41,3\%) telah melakukan pembicaraan meski tidak pernah mencapai kesepakatan bersama dan $(71,7 \%)$ subyek penelitian merasa tidak ada masalah bila gugatan cerai nantinya disetujui, namun keberadaan anak tetap merupakan sebuah masalah $(17,5 \%)$.

Tabel 3. Distribusi hasil pengukuran derajat self-kindness, self-judgment, common humanity, isolation, mind-fulness, over-identification, dan self-compassion perempuan pengaju gugatan perceraian di Pengadilan Agama Surabaya [16]

\begin{tabular}{|c|c|c|c|c|}
\hline Variabel & Kategori & Skor & $\begin{array}{l}\text { Frek.per } \\
\text { kategori }\end{array}$ & $\begin{array}{l}\text { Realatif frek.per } \\
\text { kategori - (\%) }\end{array}$ \\
\hline \multicolumn{5}{|c|}{ Self Compassion Domain Positif } \\
\hline \multirow[t]{3}{*}{ - Self-kindness } & Rendah & $5-\leq 12,5$ & 1 & 2,2 \\
\hline & Sedang & $>12,5-\leq 17,5$ & 22 & 47,8 \\
\hline & Tinggi & $>17,5-25$ & $23^{*}$ & $50,0 *$ \\
\hline \multirow[t]{3}{*}{ - Common humanity } & Rendah & $4-\leq 10$ & 1 & 2,2 \\
\hline & Sedang & $>10-\leq 14$ & 9 & 19,5 \\
\hline & Tinggi & $>14-20$ & $36^{*}$ & $78,3^{*}$ \\
\hline \multirow[t]{3}{*}{ - Mindfulness } & Rendah & $4-\leq 10$ & 2 & 4,3 \\
\hline & Sedang & $>10-\leq 14$ & 21 & 45,7 \\
\hline & Tinggi & $>14-20$ & $23^{*}$ & $50,0^{*}$ \\
\hline \multicolumn{5}{|c|}{ Self Compassion Domain Negatif } \\
\hline \multirow[t]{3}{*}{ - Self-judgment } & Rendah & $5-\leq 12,5$ & $24 *$ & $52,2 *$ \\
\hline & Sedang & $>12,5-\leq 17,5$ & 16 & 34,8 \\
\hline & Tinggi & $>17,5-25$ & 6 & 13,0 \\
\hline \multirow[t]{3}{*}{ - Isolation } & Rendah & $4-\leq 10$ & $20^{*}$ & $43,5^{*}$ \\
\hline & Sedang & $>10-\leq 14$ & 11 & 23,9 \\
\hline & Tinggi & $>14-20$ & 15 & 32,6 \\
\hline \multirow[t]{3}{*}{ - Over-identification } & Rendah & $4-\leq 10$ & 12 & 26,1 \\
\hline & Sedang & $>10-\leq 14$ & $27^{*}$ & $58,7^{*}$ \\
\hline & Tinggi & $>14-20$ & 7 & 15,2 \\
\hline \multicolumn{5}{|l|}{ Self-compassion } \\
\hline \multirow[t]{4}{*}{ - Self-compassion } & Rendah & $26-\leq 65$ & 3 & 6,5 \\
\hline & Sedang & $>65-\leq 91$ & $31 *$ & $67,4 *$ \\
\hline & Tinggi & $\geq 91-130$ & 12 & 26,1 \\
\hline & Total & & 46 & 100,0 \\
\hline
\end{tabular}

Tabel 4. Hasil distribusi pengukuran dan analisis hubungan antara Divorce Readiness Questionnaire (Natalie Gregg) dengan kuesioner kesiapan bercerai menurut kultur budaya mengacu pada Positive Psychological Assessment a Handbook of Models and Measures (Shane) pada perempuan pengaju gugatan perceraian di Pengadilan Agama Surabaya [16]

\begin{tabular}{llll}
\hline Variabel & Kategori & Frekuensi per kategori & $\begin{array}{l}\text { Realatif frekuensi } \\
\text { per kategori (\%) }\end{array}$ \\
\hline Divorce Readiness Questionnaire & & & \\
\hline Kesiapan bercerai & Tidak siap bercerai & 2 & 4,3 \\
\hline & Ragu-ragu bercerai & $30^{*}$ & $65,2^{*}$ \\
\hline
\end{tabular}




\begin{tabular}{|c|c|c|c|}
\hline & Siap bercerai & 14 & 30,5 \\
\hline \multicolumn{4}{|l|}{ Kuesioner kultur budaya } \\
\hline \multirow[t]{3}{*}{ Kesiapan bercerai } & Ragu-ragu bercerai & 2 & 4,3 \\
\hline & Siap bercerai & $44^{*}$ & $95,7 *$ \\
\hline & Total & 46 & 100,0 \\
\hline $\begin{array}{c}\text { Variabel } \\
\end{array}$ & \multicolumn{3}{|c|}{ Kuesioner kesiapan bercerai (Natalie Gregg) } \\
\hline \multirow{2}{*}{$\begin{array}{l}\text { Kuesioner kesiapan bercerai } \\
\text { (kultur budaya) }\end{array}$} & $(\mathrm{r})$ & \multicolumn{2}{|c|}{0,233} \\
\hline & (p) & & \\
\hline
\end{tabular}

Tabel 5. Hasil distribusi dan analisis hubungan antara skala self-kindness, self-judgment, common humanity, isolation, mindfulness, overidentified, dan self-compassion dengan tingkat kesiapan bercerai (menggunakan Divorce Readiness Questionnaire Natalie Gregg) dan kuesioner kesiapan bercerai menurut kultur budaya mengacu pada Positive Psychological Assessment a Handbook of Models and Measures (Shane) perempuan pengaju gugatan perceraian di Pengadilan Agama Surabaya [16,17]

\begin{tabular}{|c|c|c|c|c|c|c|}
\hline \multirow[t]{2}{*}{ Variabel } & \multicolumn{3}{|c|}{$\begin{array}{l}\text { Kesiapan bercerai } \\
\text { (Natalie Gregg) }\end{array}$} & \multirow[b]{2}{*}{ Total } & \multirow[b]{2}{*}{$\mathbf{r}$} & \multirow[b]{2}{*}{$\mathbf{p}$} \\
\hline & $\begin{array}{l}\text { Tidak siap } \\
\text { bercerai }\end{array}$ & $\begin{array}{l}\text { Ragu-ragu } \\
\text { bercerai }\end{array}$ & $\begin{array}{l}\text { Siap } \\
\text { bercerai }\end{array}$ & & & \\
\hline \multicolumn{7}{|c|}{ Self Compassion Domain Positif } \\
\hline \multicolumn{7}{|c|}{ - Self-kindness } \\
\hline Rendah & $0(0 \%)$ & $1(100 \%)$ & $0(0 \%)$ & $1(100,0 \%)$ & & \\
\hline Sedang & $1(4,5 \%)$ & $11(50,0 \%)$ & $10(45,5 \%)$ & $22(100,0 \%)$ & & \\
\hline Tinggi & $1(4,3 \%)$ & $18(78,3 \%)$ & $4(17,4 \%)$ & $23(100,0 \%)$ & $-0,200$ & 0,183 \\
\hline Total & $2(4,3 \%)$ & $30(65,3 \%)$ & $14(30,4 \%)$ & $46(100,0 \%)$ & & \\
\hline \multicolumn{7}{|c|}{ - Common humanity } \\
\hline Rendah & $0(0 \%)^{*}$ & $0(0 \%)^{*}$ & $1(100,0 \%)^{*}$ & $1(100,0 \%)$ & & \\
\hline Sedang & $0(0 \%) *$ & $6(66,7 \%)^{*}$ & $3(33,3 \%)^{*}$ & $9(100,0 \%)$ & & \\
\hline Tinggi & $2(5,6 \%)^{*}$ & $24(66,7 \%)^{*}$ & $10(27,8 \%)^{*}$ & $36(100,0 \%)$ & 0,285 & 0,055 \\
\hline Total & $2(4,3 \%)^{*}$ & $30(65,3 \%)^{*}$ & $14(30,4 \%)^{*}$ & $46(100,0 \%)$ & & \\
\hline \multicolumn{7}{|c|}{ - Mindfulness } \\
\hline Rendah & $0(0 \%)^{*}$ & $1(50,0 \%)$ & $1(50,0 \%)^{*}$ & $2(100,0 \%)$ & & \\
\hline Sedang & $0(0 \%)^{*}$ & $14(66,7 \%)$ & $7(33,3 \%)^{*}$ & $21(100,0 \%)$ & & \\
\hline Tinggi & $2(8,7 \%)^{*}$ & $15(65,2 \%)$ & $6(26,1 \%)^{*}$ & $23(100,0 \%)$ & $-0,204$ & 0,174 \\
\hline Total & $2(4,3 \%)$ & $30(65,3 \%)$ & $14(30,4 \%)$ & $46(100,0 \%)$ & & \\
\hline \multicolumn{7}{|c|}{ Self Compassion (Domain Negatif) } \\
\hline \multicolumn{7}{|c|}{ - Self-judgment } \\
\hline Rendah & $0(0 \%)$ & $17(70,8 \%)$ & $7(29,2 \%)$ & $24(100,0 \%)$ & $-0,044$ & 0,773 \\
\hline Sedang & $2(12,5 \%)$ & $8(50,0 \%)$ & $6(37,5 \%)$ & $16(100,0 \%)$ & & \\
\hline Tinggi & $0(0 \%)$ & $5(83,3 \%)$ & $1(16,7 \%)$ & $6(100,0 \%)$ & & \\
\hline Total & $2(4,3 \%)$ & $30(65,3 \%)$ & $14(30,4 \%)$ & $46(100,0 \%)$ & & \\
\hline \multicolumn{7}{|l|}{ - Isolation } \\
\hline Rendah & $0(0 \%)$ & $13(65,0 \%)$ & $7(35,0 \%)$ & $20(100,0 \%)$ & -0170 & 0,259 \\
\hline Sedang & $1(9,1 \%)$ & $6(54,5 \%)$ & $4(36,4 \%)$ & $11(100,0 \%)$ & & \\
\hline Tinggi & $1(6,7 \%)$ & $11(73,3 \%)$ & $3(20,0 \%)$ & $15(100,0 \%)$ & & \\
\hline Total & $2(4,3 \%)$ & $30(65,3 \%)$ & $14(30,4 \%)$ & $46(100,0 \%)$ & & \\
\hline \multicolumn{7}{|c|}{ - Over-identified } \\
\hline Rendah & $0(0 \%)$ & $8(66,7 \%)$ & $4(33,3 \%)$ & $12(100,0 \%)$ & & \\
\hline Sedang & $2(7,4 \%)$ & $19(70,4 \%)$ & $6(22,2 \%)$ & $27(100,0 \%)$ & 0,143 & 0,342 \\
\hline Tinggi & $0(0 \%)$ & $3(42,9 \%)$ & $4(57,1 \%)$ & $7(100,0 \%)$ & & \\
\hline Total & & & & & & \\
\hline
\end{tabular}

\begin{tabular}{|c|c|c|c|c|c|c|}
\hline \multicolumn{7}{|c|}{ Self Compassion (gabungan domain positif dan negatif) } \\
\hline \multicolumn{7}{|c|}{ - Self-compassion } \\
\hline Rendah & $0(0 \%)$ & $2(66,7 \%)$ & $1(33,3 \%)$ & $3(100,0 \%)$ & & \\
\hline Sedang & $0(0 \%)$ & $20(64,5 \%)$ & $11(35,5 \%)$ & $31(100,0 \%)$ & $-0,258$ & 0,083 \\
\hline Tinggi & $2(16,7 \%)$ & $8(66,7 \%)$ & $2(16,7 \%)$ & $12(100,0 \%)$ & & \\
\hline Total & $2(4,3 \%)$ & $30(65,3 \%)$ & $14(30,4 \%)$ & $46(100,0 \%)$ & & \\
\hline \multirow[t]{2}{*}{ Variabel } & Kesiapan b & rai (kuesioner & ultur budaya) & & & \\
\hline & $\begin{array}{l}\text { Ragu-ragu } \\
\text { bercerai }\end{array}$ & Siap bercerai & Total & $\mathbf{r}$ & & $\mathbf{p}$ \\
\hline \multicolumn{7}{|c|}{ Self Compassion Domain Positif } \\
\hline \multicolumn{7}{|c|}{ - Self-kindness } \\
\hline Rendah & $0(0 \%)$ & $1(100 \%)$ & $1(100 \%)$ & & & \\
\hline Sedang & $2(9,1 \%)$ & $20(90,9 \%)$ & $22(100,0 \%)$ & & & \\
\hline Tinggi & $0(0 \%)$ & $23(100 \%)$ & $23(100 \%)$ & 0,013 & & 0,931 \\
\hline Total & $2(4,3 \%)$ & $44(95,7 \%)$ & $46(100,0 \%)$ & & & \\
\hline
\end{tabular}




\begin{tabular}{|c|c|c|c|c|c|}
\hline \multicolumn{6}{|c|}{ - Common humanity } \\
\hline Rendah & $0(0 \%)^{*}$ & $1(100 \%)^{*}$ & $1(100 \%)$ & & \\
\hline Sedang & $0(0 \%)^{*}$ & $9(100 \%)^{*}$ & $9(100 \%)$ & & \\
\hline Tinggi & $2(5,6 \%)^{*}$ & $34(94,4 \%)^{*}$ & $36(100,0 \%)$ & $-0,059$ & 0,697 \\
\hline Total & $2(4,3 \%)$ & $4(95,7 \%)$ & $4(100 \%)$ & & \\
\hline \multicolumn{6}{|c|}{ - Mindfulness } \\
\hline Rendah & $0(0 \%)$ & $2(100 \%)$ & $2(100 \%)$ & & \\
\hline Sedang & $1(4,8 \%)$ & $20(95,2 \%)$ & $21(100 \%)$ & & \\
\hline Tinggi & $1(4,3 \%)$ & $22(95,7 \%)$ & $23(100 \%)$ & $-0,169$ & 0,261 \\
\hline Total & $2(4,3 \%)$ & $44(95,7 \%)$ & $46(100 \%)$ & & \\
\hline \multicolumn{6}{|c|}{ Self Compassion Domain Negatif } \\
\hline \multicolumn{6}{|c|}{ - Self-judgment } \\
\hline Rendah & $1(4,2 \%)$ & $23(95,8 \%)$ & $24(100,0 \%)$ & $-0,092$ & 0,541 \\
\hline Sedang & $1(6,3 \%)$ & $15(93,8 \%)$ & $16(100,0 \%)$ & & \\
\hline Tinggi & $0(0 \%)$ & $6(100,0 \%)$ & $6(100,0 \%)$ & & \\
\hline Total & $2(4,3 \%)$ & $44(95,7 \%)$ & $46(100,0 \%)$ & & \\
\hline \multicolumn{6}{|c|}{ - Isolation } \\
\hline Rendah & $0(0 \%)$ & $20(100 \%)$ & $20(100 \%)$ & $-0,118$ & 0,435 \\
\hline Sedang & $2(18,2 \%)$ & $9(81,8 \%)$ & $11(100,0 \%)$ & & \\
\hline Tinggi & $0(0 \%)$ & $15(100 \%)$ & $15(100 \%)$ & & \\
\hline Total & $2(4,3 \%)$ & $44(95,7 \%)$ & $46(100 \%)$ & & \\
\hline \multicolumn{6}{|c|}{ - Over-identified } \\
\hline Rendah & $1(8,3 \%)^{*}$ & $11(91,7 \%)^{*}$ & $12(100 \%)$ & & \\
\hline Sedang & $1(3,7 \%)^{*}$ & $26(96,3 \%)^{*}$ & $27(100 \%)$ & $-0,156$ & 0,3 \\
\hline Tinggi & $0(0 \%)^{*}$ & $7(100 \%)^{*}$ & $7(100 \%)$ & & \\
\hline Total & $2(4,3 \%)$ & $44(95,7 \%)$ & $46(100 \%)$ & & \\
\hline \multicolumn{6}{|c|}{ Self Compassion (gabungan domain positif dan negatif) } \\
\hline \multicolumn{6}{|c|}{ - Self-compassion } \\
\hline Rendah & $0(0 \%)$ & $3(100 \%)$ & $3(100 \%)$ & & \\
\hline Sedang & $2(6,5 \%)$ & $29(93,5 \%)$ & $31(100 \%)$ & $-0,170$ & 0,259 \\
\hline Tinggi & $0(0 \%)$ & $12(100 \%)$ & $12(100 \%)$ & & \\
\hline Total & $2(4,3 \%)$ & $44(95,7 \%)$ & $46(100 \%)$ & & \\
\hline
\end{tabular}

\section{DISKUSI}

\section{Hubungan self-compassion dengan kesiapan bercerai} perempuan pengaju gugatan perceraian di Pengadilan Agama Surabaya.

Tidak terdapat hubungan antara variabel selfcompassion dengan kesiapan bercerai pada perempuan pengaju gugatan perceraian di Pengadilan Agama Surabaya. Hal ini dijelaskan; Self-compassion menekan pikiran dan emosi yang tidak diinginkan melalui self-kindness, common humanity, mindfulness, dan mengakui bahwa emosi ini adalah valid dan penting. Self-compassion bukan menggantikan emosi negatif dengan emosi positif, melainkan merangkul emosi negatif $[11,12]$. Bila derajat self-compassion dikaitkan dengan kesiapan bercerai, digambarkan bahwa selfcompassion rendah seringkali membuat subyek penelitian tidak siap mempertahankan perkawinan, sebaliknya mereka dengan self-compassion tinggi justru dapat mencegah perceraian [7]. Data subyek penelitian menunjukkan bahwa semua domain positif berada pada derajat tinggi dan hampir semua domain negatif pada derajat rendah, sebenarnya memungkinkan terjadi hubungan bermakna. Namun tidak demikian halnya, mengingat ada faktor-faktor di luar kedua variabel tersebut yang dapat mempengaruhi mengapa hubungan ini tidak terjadi, yakni; 1) komitmen dan harapan perkawinan tidak sesuai realita, 2) perkawinan merupakan jenis hubungan menantang, 3) keterbatasan waktu dan usaha dalam mengembangkan keterampilan hubungan dalam perkawinan [8]. Disimpukan bahwa self-compassion subyek penelitian tidak perlu menjadi variabel utama dalam kesiapan perceraian, kemungkinan besar bahwa faktor eksternal yang justru berperan dominan dalam kesiapan perceraian mereka. Hal ini didukung melalui data karakteristik perkawinan dan hasil wawancara mendalam pada subyek penelitian, diantaranya; awal keretakan hubungan di 1-2 tahun perkawinan, lamanya konflik sudah lebih dari 10 tahun, mulainya muncul pemikiran bercerai setelah 10 tahun perkawinan, tanda-tanda depresi cukup berat di awal-awal munculnya konflik. Keterkaitan kondisi ini menghasilkan dinamika bagi subyek penelitian untuk menentukan ketegasan pilihan dalam memberanikan diri mengajukan perceraian secara hukum tanpa dipengaruhi keberadaan derajat selfcompassion, akibat berlarut-larutnya konflik tanpa kepastian 
solusi seiring dengan kuatnya kemunculan rasa ingin bercerai. Self-compassion kemungkinan akan berhubungan bermakna dengan kesiapan bercerai, bila penelitian dilaksanakan di awal-awal masa konflik perkawinan. Dengan demikian dikatakan, ada pemilihan waktu (timing) kapan selfcompassion berpengaruh secara bermakna terhadap kesiapan bercerai seseorang. Peran psikiater, psikolog, ataupun konselor perkawinan sebenarnya sangat bermakna di periode awal konflik dimana marital counseling dapat diberikan yang di dalamnya turut menyertakan pemahaman terhadap self compassion mereka dalam memperbaiki hubungan interpersonal pasangan, manajemen stres, perbaikan coping skill, stabilitas emosi, dan kesadaran dengan kondisi yang saat ini dihadapi.

\section{Perbedaan kesiapan bercerai melalui Divorce}

\section{Readiness Questionnaire (Natalie Gregg) dan kuesioner} kultur budaya.

Didapatkan hasil penelitian dengan proporsi subyek penelitian yang ragu-ragu becerai terbanyak dengan menggunakan Divorce Readiness Questionnaire (Natalie Gregg) dan proporsi subyek penelitian yang siap bercerai dengan menggunakan kuesioner kesiapan bercerai (kultur budaya). Kedua perbedaan ini dapat dipengaruhi oleh kultur budaya subyek penelitian yang seluruhnya bersuku Jawa. Keputusan bercerai tidak muncul tiba-tiba. Bahkan tidak pernah sedikitpun terbayang suatu saat akan datang ke Pengadilan Agama untuk bercerai. Hal ini muncul setelah lebih dari 10 tahun subyek penelitian berjuang memperbaiki relasi dengan pasangan. Namun seringkali usaha dilakukan tidak pernah optimal, hanya berjalan sepihak, tidak ada hasil dalam setiap pertemuan dengan pasangan, dan mereka tidak pernah berusaha mendatangi psikolog maupun psikiater (karena tabu, takut biaya tinggi, dan informasi yang kurang). Mereka juga tidak menggunakan jasa pengacara karena takut biaya yang mahal dan semakin panjangnya urusan, serta tidak berusaha didampingi alim ulama selama proses pengajuan cerai berjalan. Subyek penelitian lelah karena fungsinya sebagai pendamping suami justru berubah menjadi pencari nafkah karena kurangnya tanggung jawab pasangan, belum lagi kekerasan verbal yang hampir setiap hari dilontarkan semakin mempertajam ketidakharmonisan rumah tangga. Selama bertahun-tahun kondisi keretakan rumah tangga ditutupi dari lingkungan sekitar, lingkungan kerja, keluarga besar, bahkan orangtua mereka sendiri. Seringkali meningkatkan ritme dan frekuensi pekerjaan menjadi pengalihan rasa sakit, disamping sikap merepresi 'rahasia' keluarga inti mereka. Belum lagi label 'janda' yang tidak pernah diharapkan terjadi pada perkawinan, membuat takut dan sebisa mungkin mereka hindari. Subyek penelitian yang semuanya bersuku Jawa masih menganggap bahwa perceraian sesuatu yang memalukan dan stigma, merasa bersalah karena restu orangtua tidak bisa melanggengkan perkawinan, malu terhadap anggapan orang lain karena tidak mampu merawat keluarga, merasa satu-satunya kesalahan ada di pihak istri. Namun dinamika perkawinan yang rumit membuat pemikiran ini tertutupi saat kebulatan tekad bercerai sangat kuat mendominasi pikiran. Beberapa ajaran Jawa yang diturunkan orangtua masih terbawa dalam kehidupan modern mereka, dimana orang Jawa sangat mengedepankan orang lain daripada dirinya sendiri; harus membuang jauh keinginan menang sendiri; dan harus memperhatikan perasaan orang lain; dan takut terhadap 'walat' (celaka) karena telah melakukan sakit hati orang lain dengan pengajuan cerainya. Teori self-construal melihat bahwa perilaku individu dipengaruhi cara individu itu sendiri dalam memandang dirinya, memandang orang lain, dan memandang hubungannya dengan orang lain [13]. Self-construal sangat terkait dengan budaya [14], dimana budaya timur yang kolektivis dan budaya barat yang individualistis berkontribusi pada tipe self-construal seperti apa yang dimiliki individu dari budaya tersebut. Subyek penelitian dapat memiliki kedua tipe construal secara simultan, dimana tipe selfconstrual mana yang lebih dominan tergantung pada tipe mana yang lebih sering diaktifkan dan menjadi norma perilaku pada budaya mereka. Dominasi ini juga dipengaruhi kognitif dan situasi yang sedang berlangsung $[15,19]$.

Meski ajaran Jawa sepintas melemahkan subyek penelitian, namun ada hal-hal yang menguatkan mereka untuk siap bercerai, diantaranya; restu orangtua setelah mereka mengemukakan kebulatan tekad bercerai, dan kesadaran kuat untuk terus bekerja agar tercapai keinginan pribadinya (sesuai ajaran Jawa). Namun, self-construal tipe kolektivis yang selama ini fleksibel mengikuti perjalanan perkawinan subyek penelitian selama bertahun-tahun, akhirnya dilemahkan oleh dominasi self-construal tipe individual terutama dalam hal pengambilan keputusan, gaya berhubungan sosial, 
meningkatkan peran diri, dan pemikiran terkait pertimbanganpertimbangan penting. Kesadaran mereka bahwa kesabaran ada batasnya, upaya perbaikan tidak pernah ada, dan mereka masih berani mandiri, maka ketegasan bercerai adalah pilihan yang dijatuhkan.

Kerbatasan penelitian adalah: 1) kurangnya menggali pertanyaan pada subyek penelitian terkait saat konflik berjalan di tahun ke 3 , ke 5, dan ke 7 periode perkawinan, mengingat periode-periode ini adalah masa rentan perkawinan dengan munculnya gambaran konflik yang khas serta penyelesaian masalah sementara pada pasangan; 2) Subyek penelitian seluruhnya bersuku Jawa, sehingga diperlukan lebih lanjut penelitian sejenis dengan populasi yang lebih luas dengan berbagai suku yang ada di Indonesia agar kuesioner kesiapan bercerai berbasis kultur budaya dapat digunakan bagi seluruh masyarakat Indonesia; 3) Belum semua faktor perancu dikendalikan dalam penelitian ini, sehingga diperlukan penelitian lebih lanjut untuk menganalisis faktor-faktor perancu mana yang sebenarnya berpengaruh terhadap keterkaitan hubungan antara selfcompassion dengan kesiapan bercerai ini.

\section{KESIMPULAN}

Tidak ada hubungan antara self-compassion dengan kesiapan bercerai pada perempuan pengaju gugatan perceraian di Pengadilan Agama Surabaya. Perlunya penelitian lebih lanjut terkait pengaruh faktor-faktor yang berperan pada self-compassion terhadap kesiapan bercerai dan memperluas populasi penelitian di masyarakat umum (di luar lembaga pengadilan agama dan negeri) agar didapatkan variasi persepsi subyek penelitian untuk memperluas wawasan dan mempertajam analisis penelitian.

\section{DAFTAR PUSTAKA}

[1] Chairy, L. S. , Psikologi suami-istri. Depok: Makalah seminar pada kursus persiapan perkawinan (KPP) Santo Paulus, 2005.

[2] Seltzer, L., "What if your ambivalence can't be resolved?," Diunduh dari : https://www.psychologytoday.com/blog/evolution-theself/201402/what-if-your-ambivalence-can-t-beresolved, 2012.
[3] Dombeck, M., "Relationship problems: ambivalence. MentalHelp.net.," Diunduh dari: https://www.mentalhelp.net/articles/relationshipproblems-ambivalence/, 2006.

[4] Neff, K. D., "The science of self-compassion," in Compassion and Wisdom in Psychotherapy, C. Germer., New York: Guilford Press, 2012, pp. 79-92.

[5] Neely, M. E., Schallert, D. L., Mohammed, S. S, Robert, R. M., Chen, Y., Self-kindness when facing stress: The role of self-compassion, goal regulation, and support in college students'well being. Motivation and emotion, no. 33. 2009.

[6] Neff, K. D., Development and validation of a scale to measure self-compassion. Self and identity, no. 2. 2003.

[7] Cox, M., \& Burford, M., "Divorce: The forgotten injury - psychiatry," Color. Chiropr. J., vol. 2, no. 6, 1997.

[8] Damayanti, I., "Perceraian : penyebab dan akibatnya. Alasan perceraian-intisari lengkap psikolog. Psikologi kita dimana sahabat berbagi.," Diunduh dari: http://psikologikita.com/?q=perceraian-penyebabakibat, 2012.

[9] Haynes, J. M., Divorce mediation: A practical guide for therapists and counselors. New York: Springer, 1981.

[10] Ahrons, C. \& Rodgers, R. H., Divorced families: a multidisciplinary developmental view. New York: W.W. Norton, 1987.

[11] Cano, A., \& O’Leary, K. D., "Infidelity and separations precipitate major depressive episodes and symptoms of nonspecific depression and anxiety," $J$. Consult. Clin. Psychol., no. 68, pp. 774-781, 2000.

[12] Neff, K. D., Kirkpatrick, K. L., \& Rude, S. S., "Selfcompassion and adaptive psychological functioning," J. Reseach Personal., no. 41, pp. 139-154, 2007.

[13] Markus, H. R \& Kitayama, S., "Culture and the self. Implications for cognitions, emotion, and motivation.," Psychol. Rev., no. 98, pp. 224-253, 1991.

[14] Kam, C., Zhou, X., Zhang X., Yee, M., Examining the dimensionality of self-construals and individualistic-collectivistic values with random 
intercept item factor analysis, Personalit. Department of Psychology, The University of Western Ontario, London, Ontario, Canada N6A 5C2, 2012.

[15] Triandis, H. C., "Cultural syndromes and subjective well-being," in Culture and subjective well-being, Diener \& S., Cambridge: Massachusetts: The MIT Press, 2000.

[16] Gregg N. Divorce Readiness Questionnaire. Natalie Gregg Family lawyer, Entrepreneur and Mother of Two. Diunduh dari http://www.huffingtonpost.com/nataliegregg/divorce_ b_1739302.html. 2012.

[17] Shane, J., Lopez \& C. R. Synder. Positive psychological assessment a handbook of models and measures. Washington, DC: American psychological association; 2003.

[18] Theresia, A. G. \& Veronika S. Gaya penyelesaian perkawinan pada pasangan dual earner (marital conflict resolution style in dual earner couples). Fakultas Psikologi Universitas Airlangga J Psikol dan Perkemb. 2014;3(3).

[19] Rufaedah A. Hubungan antara self-construal dan subjective well being padaetnis Jawa (correlation betweem self-construal and subjective well-being on Javaness ethnic). Depok: Fakultas psikologi program studi ilmu psikologi peminatan psikologi sosial. Universitas Indonesia; 2012. 